Milica Tapavički-Ilić

Arheološki institut Beograd

Mirjana Arsenijević

Arheološki institut Beograd

904:631"652"(497)

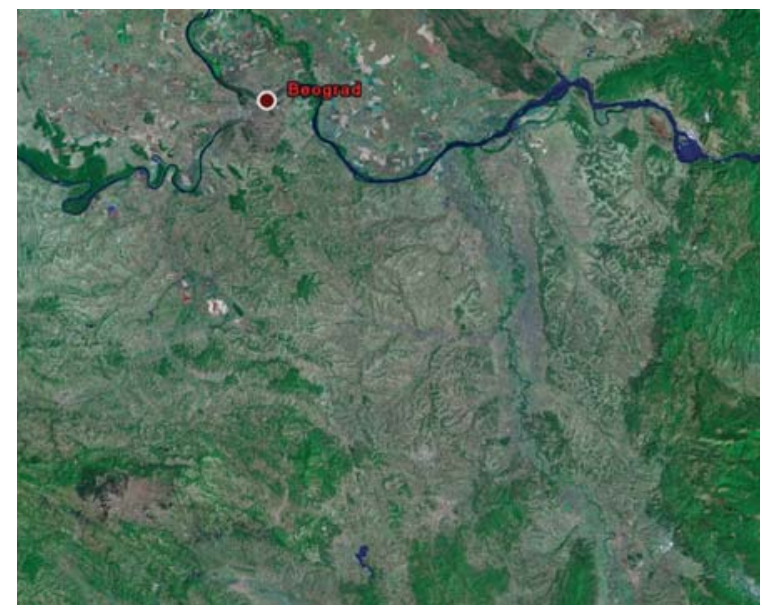

\title{
POLJOPRIVREDA CENTRALNOG BALKANA NA PRELASKU STARE U NOVU ERU
}

\begin{abstract}
ABSTRAKT
Rad se bavi promenama u poljoprivredi koje su se na prelasku Stare u Novu eru odvijale na prostoru centralnog Balkana, odnosno na prostoru koji su tada naseljavali Skordisci. S obzirom da je ovaj aspekt materijalne kulture u srpskoj arheologiji malo proučen, izgrađen je model putem poređenja sa srodnim istraživanjima u centralnoj Evropi. U oba slučaja, glavni izvor građe bili su grobni nalazi. Kao najupečatljivija promena do koje je nakon rimske okupacije došlo u centralnoj Evropi jeste pojava baštenskih kultura, pa se sa sličnom pojavom može računati i na području centralnog Balkana.

Prilikom ovog istraživanja su takođe proučeni kriterijumi koji su mogli biti korišćeni za izbor određenih biljnih vrsta, kao što su ekološki faktori (klima, kvalitet tla), tehnološki, ekonomski, socijalni i drugi faktori.
\end{abstract}

\section{KLJUČnE REČI: ARHEOBotanika, Kelti, Skordisci, RimlJani}

Za mnoga društva, pa i za ona koja su se razvijala i postojala u periodu prelaska Stare u Novu eru, poljoprivreda predstavlja egzistencijalnu osnovu. Rekonstrukcija poljoprivrednog potencijala stoga predstavlja jedan od centralnih faktora za razumevanje toka rimskog uticaja na poljoprivredu domorodačkog stanovništva. ${ }^{1}$

Značaj različitih biljaka i životinja je višestruk: one su korišćene za ishranu i kao sirovine, dok su sa druge strane imale važnu ulogu u ritualu i medicini. U direktnoj vezi sa poljoprivredom stoji i način ishrane, koji je karakterističan za svako 1. Kreuz 1995a, 59. društvo ponaosob i koji uvek uključuje samo određene životinjske i biljne vrste.

Očigledno, reč je o složenom problemu, kod kojeg je potrebno sagledati više aspekata. Prilikom njegovog proučavanja, pojavila su se sledeća pitanja: ${ }^{2}$

- koje su biljne vrste najčešće uzgajali Kelti, a koje Rimljani?

- postoji li tipično "keltska" ili tipično "rimska" poljoprivreda?

2. Kreuz 1995a, 59. 
- da li se biljne vrste prisutne tokom prelaska Stare u Novu eru na rimskim poljoprivrednim dobrima (villae rusticae) i u selima (vici) razlikuju od onih konstatovanih u drugim naseljima čija je primarna delatnost takođe poljoprivreda?

- može li se pomoću ustanovljenih biljnih vrsta utvrditi da li je došlo do promena u poljoprivredi i do ekoloških promena koje bi se javile kao posledica toga?

- postoje li razlike u upotrebi određenih biljnih vrsta, koje bi se npr. ogledale u korišćenju određenih biljnih vrsta samo u ishrani ili samo u kultu?

$$
* * *
$$

Istraživanja ove problematike trebalo bi da obuhvate ispitivanja klime, tla i reljefa, kao i analize polena. Od velikog značaja bi tu bile druge nauke, kao klimatologija, geografija ili botanika. Da li se klima na prelasku Stare u Novu eru razlikovala od današnje, da li je bila blaža ili surovija i da li je onda bilo više ili manje padavina nego danas? Da li je kvalitet tla tada bio bolji nego što je to danas slučaj ili se pri obradi zemlje nailazilo na izuzetno velike teškoće? Kakva je bila struktura tla? Poseban značaj imaju analize polena, koje mogu da pokažu da li je dolazilo do promena u regionalnoj vegetaciji, a koje bi dalje mogle da ukažu na kontinuitet ili diskontinuitet u naseljavanju i korišćenju jedne određene oblasti.

Prelaz iz gvozdenog doba u rimski period i razvoj vegetacije u prvim vekovima posle Hrista različito su se odvijali u različitim oblastima. Na nekim mestima je uočljiv diskontinuitet u stanovanju, kao što to pokazuje Roš ${ }^{1}$ za oblast Bodenskog jezera. Ovde je na kraju gvozdenog doba, a pre nastanjivanja Rimljana, ustanovljen prekid u nastanjivanju, jer je došlo do regeneracije šuma. Nasuprot tome, za oblast oko Luterskog jezera u Ajhsfeldu, Bojg² dokazuje da nema prekida u nastanjivanju, jer su ispitivanjima utvrđeni sve veći i veći indikatori ljudskog uticaja. Na početku rimskog perioda je ovde došlo do izuzetno jakog razvoja poljoprivrede.

1. Rösch 1992, 101-109.

2. Beug 1992, 315.
Iz perioda prelaska Stare u Novu eru, sa područja Zapadne i Centralne Evrope, poznate su 233 vrste kultivisanih i korisnih biljaka. ${ }^{3}$ Od ovih su najbolje poznate one koje su uzgajali i konzumirali Rimljani, odnosno one koje su otkrivene na rimskim lokalitetima. Tu spada osam vrsta žitarica, ${ }^{4}$ tri vrste mahunastih plodova ${ }^{5}$ i četiri uljarice tj. vlaknaste biljke. ${ }^{6}$ Dalje, utvrđeno je postojanje petnaestak vrsta voća uglavnom uzgajanih u baštama, ${ }^{7}$ šesnaest vrsta lekovitih biljaka i začina, ${ }^{8}$ kao i jedna biljka od koje se dobija žuta boja. ${ }^{9}$ Poznato je bilo dvanaest vrsta divljeg i koštunjavog voća, ${ }^{10}$ ali i neke biljke za koje se sa sigurnošću može tvrditi da su bile uvožene, ${ }^{11}$

3. Kreuz 1995a, 64.

4. Kreuz 1995a, 70, nap. 49. Ječam (Hordeum vulgare), raž (Secale cereale), hlebna pšenica (Triticum aestivum), dvozrna pšenica (Triticum dicoccuum), pšenica (Triticum spelta), proso (Panicum miliaceum), jednozrna pšenica (Triticum monococcum) i proso u klipu (Setaria italica).

5. Kreuz 1995a, 70, nap. 50. Sočivo (Lens culinaris), grašak (Pisum sativum) i bob (Vicia faba).

6. Kreuz 1995a, 70, nap. 51. Konoplja (Cannabis sativa), lan (Linum usitatissimum), mak (Papaver somniferum) i (Camelina sativa).

7. Kreuz 1995a, 70, nap. 52. Dinja (Cucumis melo), smokva (Ficus carica), orah (Iuglans regia), jabuka (Malus domestica), mušmula (Mespilus germanica), trešnja (Prunus avium), šljiva (Prunus domestica ssp. insititia), ringlov (Prunus domestica ssp. oeconomica), breskva (Prunus persica), kruška (Pyrus communis), glog (Sorbus aria), oskoruša (Sorbus domestica), brekinja (Sorbus torminalis), vinova loza (Vitis vinifera) i bundeva (Lagenaria siceraria).

8. Kreuz 1995a, 70, nap. 53. Osam začina: mirođija (Anethum graveolens), celer (Apium graveolens), kim (Carum carvi), koriander (Coriandrum sativum), kopar (Foeniculum vulgare), vinska rutvica (Ruta graveolens), senf (Sinapis arvensis) i (Satureia hortensis).

Osam lekovitih biljaka: velebilje (Atropa bella-donna), kukuta (Conium maculatum), dimnja (Fumaria officinalis), bunika (Hyoscyamus niger), kantarion (Hypericum perforatum), slez (Malva), divlja vrbena (Verbena officinalis) i (Peucedanum officinale).

9. Kreuz 1995a, 70, nap. 54. Katančica (Reseda luteola). 10. Kreuz 1995a, 70, nap. 55. Lešnik (Corylus avellana), glog (Cratageus laevigata), bukva (Fagus sylvatica), jagoda (Fragaria vesca), trnjina (Prunus spinosa), ogrozd (Ribes cf. uva crispa), šipak (Rosa spec.), ostužnjak (Rubus caesius), kupina (Rubus fruticosus), malina (Rubus iadeus), zova (Sambucus nigra) i borovnica (Vaccinium cf. myrtillus).

11. Kreuz 1995a, 70, nap. 56. Radi se o maslinama (Olea europaea) i semenju četinara (Pinus pinea) iz Mediteran- 
jer zbog klimatskih uslova nisu mogle biti uzgajane izvan Mediteranskog područja. ${ }^{12}$ Kod nekih vrsta se ne može pouzdano utvrditi da li su bile uvožene ili uzgajane na licu mesta, kao npr. dinja (Cucumis melo). ${ }^{13}$

$\mathrm{Na}$ gvozdenodopskim lokalitetima zapadne i centralne Evrope otkriveno je sedam vrsta žitarica, ${ }^{14}$ četiri vrste mahunastih ${ }^{15} \mathrm{i}$ dve vrste uljanih tj. vlaknastih biljaka, ${ }^{16}$ čemu treba dodati još četiri biljne vrste do kojih se dolazilo sakupljanjem. ${ }^{17}$ Iz ovoga se nameće jasan zaključak da je osnovna razlika između gvozdenodopskih i rimskih nalaza u nedostatku začina, povrća i voća koje se uzgaja u baštama. Pojava kultivisanih baštenskih biljaka može se smatrati delom procesa romanizacije, što takođe uključuje promenu u duhovnom smislu koja podrazumeva početak uzgajanja hranljivih biljaka. Pri tome se uzgajaju biljke kod kojih je potreban dugogodišnji rad pre nego što bi dale prve plodove, kao šljiva ili breskva, ili koje moraju biti negovane pažljivo i pod posebnim uslovima, kao dinja ili bundeva. Repice takođe spadaju u baštenske kulture i zahtevaju intenzivno đubrenje. Preduslov za uvođenje ovih novina bilo je i poznavanje kalemljenja.

U periodu prelaska Stare u Novu eru sigurno je došlo do neke vrste demilitarizacije domorodačkih plemena. U jednom relativno kratkom periodu, ratnički sloj domorodačkog stanovništva je prestao da postoji, što je automatski značilo porast radne snage za poljoprivredne i zanatske delatnosti i za

skog područja, kao i o biberu (Piper nigrum), koji je u područje centralne Evrope verovatno došao iz Indije.

12. Kreuz 1995a, 70.

13. Körber-Gröhne 1987, 454.

14. Kreuz 1995a, 70, nap. 59. Ječam (Hordeum vulgare), hlebna pšenica (Triticum aestivum), dvozrna pšenica (Triticum dicoccum), pšenica (Triticum spelta), proso (Panicum miliaceum), jednozrna pšenica (Triticum monococcum) i proso u klipu (Setaria italica).

15. Kreuz 1995a, 70, nap. 60. Sočivo (Lens culinaris), grašak (Pisum sativum), bob (Vicia faba) i grahorica (Vicia ervilia).

16. Kreuz 1995a, 70, nap. 61. Lan (Linum usitatissimum) i (Camelina sativa).

17. Kreuz 1995a, 70, nap. 62. Lešnik (Corylus avellana), srezma (Prunus padus), malina (Rubus iadeus) i zova (Sambucus nigra). trgovinu. To je dovelo do napretka poljoprivrede, u koju se ulagalo više znanja, radnog vremena i energije. Kao primer se ovde može navesti uzgoj vinove loze, koja je u rimskom periodu potvrđena u pojedinim oblastima, a za koju je u proseku po hektaru potrebno tri puta više rada nego za uzgoj žitarica.

Naravno, veliki broj pitanja i dalje ostaje bez odgvora, npr. u koje vremenske okvire treba svrstati uvođenje baštenskih i voćnih kultura i uvoz egzotičnih jestivih biljaka? Jesu li nove vrste biljaka uzgajali samo novopridošli Rimljani ili su domoroci takođe prihvatili i uzgajali ove biljne vrste? Jesu li nove vrste bile svuda rasprostranjene ili su bile uzgajane samo u određenim oblastima? Ako su svuda bile rasprostranjene, koliko je vremena moralo da prođe dok su one dostigle taj nivo?

Zanimljiva je konstatacija da su neke od "novih" vrsta, kao npr. divlji kelj (Brassica oleracea), prirodno rasle na obalama Severnog i Sredozemnog mora, kao i na Atlantiku. Zato su Kelti, podjednako kao i Rimljani, imali mogućnost da ovu biljku kultivišu, ali to nisu učinili. Tako su mogli da kultivišu i vinovu lozu (Vitis vinifera ssp. sylvestris), koja raste u dolinama reka, ali su ipak uvozili skupo gotovo vino. Na pitanje zašto je to bilo tako, treba tek odgovoriti. Da li Kelti nisu imali dovoljno znanja da bi izvršili kultivaciju, ili su sebi radije priuštili gotove proizvode? Ne sme se zaboraviti da u vezi sa proizvodnjom vina ne stoji samo uzgoj vinove loze, nego i čitava tehnologija fermentacije grožđa, spravljanja vina itd. To bi značilo da sam uzgoj vinove loze, bez daljeg znanja i mogućnosti spravljanja vina, ne bi bio dovoljan. Još jedan jednostavan razlog bi bio da možda domaće vino nije imalo tako dobar ukus kao ono iz Italije.

Vrlo je važno pitanje koji su kriterijumi uticali na izbor kultivisanih biljaka. Tu su najpre od važnosti ekološki faktori, kao što su klima, kvalitet tla i dr., a na koje uzgajivač gotovo da nema uticaja. Ono što se u najširim okvirima može smatrati kao presudno za izbor ove ili one biljne vrste su tehnički, ekonomski i socijalni faktori, kao 
npr. prinos, trajanje rasta i mogućnosti korišćenja zasađenih biljaka, obim neophodnih pripremnih radova, raspoloživa radna snaga, sistem trgovine i tržišta i tehnološko stanje poljoprivrede. U obzir treba uzeti i odnose sa stočarstvom. ${ }^{1}$

Najviše prinose daju pšenica, raž, ječam i zob. Pšenica i ječam ne uspevaju dobro na posnom zemljištu i slabo su otporni na bolesti i štetočine. Nasuprot tome, izdašna i relativno rezistentna raž podnosi posno zemljište i nepovoljne klimatske uslove. Od ove četiri žitarice, pšenica daje najveći prinos, ali je vezana za određene vrste zemljišta i ima vrlo ograničenu sposobnost podnošenja hladne klime. Veliki spektar podvrsti ječma pruža mogućnost za prilagođavanje na klimu i različit kvalitet tla. On toleriše slano, kao i peskovito ili tresetno zemljište, a kao letnja žitarica poseduje izuzetno kratko vreme rasta od samo devet nedelja. Emer (Triticum dicoccum) i jedna vrsta pšenice (Triticum spelta) pripadaju žitaricama sa srednjim prinosom, ali zato poseduju veću otpornost na bolesti.

$\mathrm{U}$ rimskom periodu je postojala povećana potreba za hlebnim žitaricama, koja je mogla biti zadovoljena uzgojem raži (Secale cereale) i pšenice (Triticum spelta) kao ozimih žitarica. Možda je u rimskom periodu bila povećana i potreba za slamom, jer se povećao broj domaćih životinja, pre svega konja, za koje je preko zime bila potrebna hrana.

Kod prosa, uljanih i mahunastih biljaka, između gvozdenog doba i rimskog perioda za sada se ne može povući jasna razlika u uzgoju. ${ }^{2}$ Ovde treba navesti i one vrste koje Rimljani na italskom prostoru prvobitno nisu koristili, kao što su jedna vrsta pšenice i raž. Uzgoj pšenice više odgovara nekoj autohtonoj, npr. keltskoj poljoprivredi, na šta ukazuju nalazi sa nekoliko lokaliteta. ${ }^{3}$

Nasuprot tome, ni na keltskom ni na italskom području nije utvrđeno kultivisanje raži u predrimsko doba. Čini se da se raž u poslednjim ve-

1. Kreuz 1995a, 76.

2. Kreuz 1995a, 77.

3. Kreuz 1995a, 76, nap, 83. kovima pre naše ere nije nalazila među ozimim žitaricama, već se sa njenim uzgojem otpočelo tek kasnije, u klimatski povoljnim oblastima unutar Rimskog carstva. Ne treba isključiti ni mogućnost preuzimanja ove žitarice od istočnoevropskih ili germanskih naroda. Nalazi raži se u okviru Limesa mogu tumačiti kao povratni uticaj domorodaca na osvajače. ${ }^{4}$

Nakon trgovaca, rimska vojska je najčešće bila ta sa kojom su domorodačke populacije dolazile u dodir. Naravno, razni uticaji su se upravo sa vojske prenosili na domorodačko stanovništvo. U vezi sa ovim stoji pitanje kojem je uticaju rimske vojske mogao biti izložen poljoprivredni potencijal jedne agrarne zajednice? Da li je rimska vojska od samog početka, osvojivši jednu određenu teritoriju, koristila poljoprivredne proizvode domorodačkog stanovništva, ili je za sebe i za životinje koje su bile prateći deo pojedinih vojnih jedinica nabavljala hranu sa nekog drugog mesta? Verovatno je da je jako brzo došlo do korišćenja lokalnih prehrambenih potencijala, najpre za životinje, a zatim i za samu vojsku.

Dalje se javlja pitanje, kakvu je ulogu u poljoprivredi imala vojska kao radna snaga? Da li je samo domorodačko stanovništvo bilo aktivno u ovoj delatnosti ili su rimski vojnici, bar delimično, imali učešća u ovim radovima. Da li je vojska morala da krči velike šume da bi došla do većih obradivih površina? To bi moglo biti verovatno, jer se na taj način automatski dolazilo i do drveta za gradnju. Da li je vojska, ako je učestvovala u poljoprivrednim radovima, preuzimala i koristila biljne vrste domorodačkog stanovništva, ili je odmah sadila i uzgajala biljne vrste koje je eventualno donela sa sobom?

Zbog povoljnog položaja na putevima koji su vodili do rimskih trupa stacioniranih duž granice Carstva, mnoga naselja su se razvila u postaje, na kojima je dolazilo do razmene robe iz gotovo svih delova Carstva. Na takvim mestima se naseljavao veliki broj trgovaca, kupaca, prevoznika i

4. Kreuz 1995a, 76. 
zanatlija. Za okolno stanovništvo se pružala povoljna mogućnost da prodaju svoje i da razmenom dobiju ili kupe strane proizvode. Pojedina naselja su tako istovremeno predstavljala i neku vrstu tržnice. ${ }^{5}$ Izgradnja puteva, koja je usledila nakon Cezarovih osvajanja i uspostavljanja novog poretka, pospešivala je privredni i politički razvoj starih zaselaka i kultnih mesta, koja su zahvaljujući svom povoljnom položaju na ovim putevima dobijala na značaju. Od 1. do 3. veka n.e. u oblasti evropskog dela Carstva treba računati sa sasvim zadovoljavajućim snabdevanjem stanovništva žitaricama. Čitav niz trgovaca, koji u isto vreme deluju i kao prevoznici, dopremao je proizvode do potrošača. ${ }^{6}$

\section{$* * *$}

Sa teritorije koju su nastanjivali Skordisci poznat je samo jako mali broj arheobotaničkih nalaza koji bi mogli dati podatke o poljoprivredi kasnog gvozdenog doba. Ipak, nalazi plugova, lopata, motika i srpova ukazuju na to da je poljoprivreda bila razvijena. Oblast Skordiska je u poslednjim vekovima pre Nove ere bila šumovita, ispresecana dolinama reka, čija je okolina često bila močvarna. Obradiva zemlja se dobijala krčenjem, iako bi se tada brzo ispostila, tako da su ubrzo morale biti krčene nove površine. To je dovelo do razvoja većeg broja manjih otvorenih naselja, koja su bila povezana sa jednim većim centrom.

Tokom iskopavanja na Gomolavi u Sremu, 1955-te, između 1967. i 1972., kao i 1979. godine sakupljeno je i ispitano nekoliko ugljenisanih biljnih ostataka iz ukupno četiri probe. ${ }^{7}$ Ukupno je identifikovano 19 biljnih vrsta. ${ }^{8}$ Jedna proba

5. Cüppers 1974, 238.

6. Cüppers 1974, 240.

7. Боројевић 1988, 111.

8. Боројевић 1988, 113. Od žitarica: jednozrna pšenica (Triticum monococcum), dvozrna pšenica tj. emer (Triticum dicoccum), pšenica (Triticum spelta), hlebna pšenica kompaktnog klasa (Triticum aestivo-compactum), proso (Panicum miliaceum), raž (Secale cereale), ječam (Hordeum vulgare) i zob (Avena fatua/sativa). Od mahunarki: sočivo (Lens culinaris) i grašak (Pisum sativum). Od korova: obična pepeljuga (Chenopodium $c f$. album), srcolika pepeljuga (Chenopodium hybridum), dvornik (Polygonum potiče iz kružnog grupnog groba.

Glavna žitarica u svim probama bila je proso (Panicum miliaceum). Ječam (Hordeum vulgare) i pšenica (Triticum spelta) su takođe zastupljeni u velikoj meri, ali uvek manje nego proso (Panicum miliaceum). Osim semenja, kod ovih žitarica su mogli biti ustanovljeni i delovi klasja, koje je tvrđe od samog semenja i često je očuvano usled ugljenisanja.

Proso je letnja žitarica, dok se ječam i pšenica mogu saditi i kao letnji i kao ozimi usevi. Treba obratiti pažnju i na činjenicu da ječam i pšenica posle žetve ostaju u zemlji, što bi značilo da je slučajno dolazilo do primesa u glavnoj žitarici. To bi dalje značilo da se prilikom obrade njiva u periodu gvozdenog doba primenjivala rotacija useva. Ipak, postoji mogućnost da su se ječam i pšenica naknadno mešali u silosima. Ječam se, kao vrsta neophodna za dobijanje piva, može direktno vezati za Kelte, za koje je iz pisanih izvora poznato da su konzumirali ovaj napitak.

Žitarice i mahunaste biljke koje se pojavljuju u malim količinama smatraju se slučajnim primesama i mogu se porediti sa korovima, iako su prvi, za razliku od drugih, uvek jestivi. Kao što je već rečeno, jedna od proba potiče iz kružnog grupnog groba, iz kojeg su prikupljena samo tri semena. Sva tri pripadaju zobi (Avena fatua/sativa). Na žalost, svi ostali podaci vezani za ovaj nalaz još uvek su neobjavljeni.

$$
* * *
$$

Biljni ostaci su poznati sa nekoliko nekropola zapadne i centralne Evrope, jer je kako kod Kelta, tako i kod Rimljana bio običaj da se u grob stavljaju prilozi u jelu i piću. Struk ${ }^{9}$ razlikuje primarne priloge, koji su stajali u vezi sa kremacijom pokojnika, od sekundarnih, koji su u grob polagani tek nakon kremacije. Primarni biljni prilozi su bivali

cf. convolvulus), ptičiji dvornik (Polygonum aviculare), obični klasač (Bromus cf. secalinus), ljulj (Lolium sp.), kukolj (Agrostema ghitago), letnji različak (Centaurea cf. solistitialis) i složenocvetnice (Compositae).

9. Struck 1993, 82-83. 
sačuvani usled ugljenisanja prilikom kremacije, dok su sekundarni prilozi neugljenisani dospevali u zemlju i brzo bivali razgrađeni dejstvom mikroi drugih organizama.

Žitarice spadaju u najčešće grobne priloge u rimskom periodu i sreću se na $40 \%$ nalazišta. ${ }^{1}$ Podjednako su učestali divlje i koštunjavo voće, kao i mahunaste biljke. Nedostaju nalazi uljanih biljaka, što bi se moglo tumačiti i kao posledica loše očuvanosti. Žitarice, uljane i mahunaste biljke, divlje i koštunjavo voće predstavljaju grupe koje se javljaju ne samo u keltskim, već i $\mathrm{u}$ germanskim grobovima. U tom smislu oni ne predstavljaju indikatore rimskog uticaja u oblasti pogrebnog rituala - naprotiv, ovde se jasno vidi da u ritualu postoji kontinuitet.

Među prilozima je često zastupljeno "rimsko" kultivisano voće, npr. breskva, šljiva i lešnik, ili one vrste koje nisu uzgajane severno od Alpa, kao urme ili masline. Vrste koje spadaju u kultivisane ili baštenske biljke, ili pak one koje su bile predmet trgovine, odlični su pokazatelji kontinuiteta u smislu pogrebnih običaja, ali ne i grobnih priloga. Te biljne vrste iz mediteranskog, ili čak nekog vrlo udaljenog prostora, u oblast srednje Evrope dolaze tek u rimskom periodu. Zato prilaganje egzotičnih biljaka ne može biti povezano sa predrimskim tradicijama.

Prilaganje ovakvih biljaka zastupljeno je samo u malom broju grobova. ${ }^{2}$ Nalazišta bez tipično rimskih grobnih priloga su u geografskom i vremenskom smislu brojna i stiče se utisak da prisustvo ili odsustvo ovih priloga nije stajalo u vezi sa bogatstvom pokojnika. Uočljivo je da su se i u jako bogatim i dobro očuvanim grobovima, iz kojih su mogle biti uzete obimne probe, nalazile samo uobičajene kultivisane biljke, ali ne i rimske uvozne. To ne treba tumačiti ni kao posledicu godišnjeg doba, jer su npr. urme i smokve kao suvo voće mogle biti nabavljane tokom cele godine. Čini se da se prilaganje rimskih vrsta voća zaista može tumačiti kao stepen romanizacije

1. Kreuz 1995b, 96.

2. Kreuz 1995b, 96. pokojnika i njegove porodice. $^{3}$

Iz ovog razloga bi bilo važno uporediti biljke iz grobova sa onim iz obližnjih naselja, jer se tako može ustanoviti različitost u stepenu promena do kojih je došlo. Može se pretpostaviti da su npr. u svakodnevnom životu, na tržištu u ponudi bile nove, rimske vrste biljaka, ali da su u pogrebnom ritualu zadržane tradicionalne, keltske vrste. Dalje, treba imati u vidu kriterijum na osnovu kojeg je vršen izbor takvih grobnih priloga - da li su postojali određeni klišei po kojima se plodovi stavljaju u grob, ili su to jednostavno bili plodovi koje je pokojnik za života rado jeo.

Napred navedena ispitivanja mogla bi da posluže kao polazna tačka za ispitivanja te vrste na području centralnog Balkana. Rezultati do kojih se dolazi ovim putem vrlo su dragoceni i ukazuju na aspekte do kojih se klasičnim sredstvima kojima se arheologija služi ne može doći. Arheobotanika bi u budućim istraživanjima na području centralnog Balkana trebalo da nađe svoje mesto, jer se do sada nalazila u senci uobičajenih metoda rada na terenu.

\section{AGRICULTURE ON THE CENTRAL BALKANS DURING TRANSITION OF THE ERAS}

This paper deals with changes which took place after the Roman occupation in the native Late Iron Age agriculture at the Mid Balkans, i.e. in the Celtic Scordisci. Since this aspect of Late Iron Age material culture is not very well examined for this region, a theory has been constructed by comparing finds from this territory to the finds from the Mid European region. The most valuable sources for both regions were grave finds. Apart from species grown at the original territory, one also encounters traces of imported plant species, like olives, peper or dates.

During the Late Iron Age, the main species grown in the Scordisci were millet, barley and wheat. Similar situation can also be observed in

3. Kreuz 1995b, 96. 
the Mid European Celtic tribes. After the Roman occupation, the main change which occured in the Middle Europe is growing garden plants. According to this, one can expect a similar change in the Mid Balkan region.

Other aspects of such changes have also been discussed, like criteria which were used for choosing certain cultivated plants. They include ecological factors (climate, soil quality), technological, economic, social factors etc.

Translated by M. Tapavički-Ilić

\section{BIBLIOGRAFIJA}

\section{Beug 1992}

Beug H-J., Vegetationsgeschichtliche Untersuchungen über die Besiedlung im Unteren Eichfeld, Landkreis Göttingen, vom frühen Neolithikum bis zum Mittelalter, Neue Ausgrabungen und Forschungen Niedersachsen 20, 1992.

\section{Боројевић 1988}

Боројевић К., Анализе угљенисаног семења из латенског насеља на Гомолави, из Јовановић Б. и Јовановић М., Гомолава, Београд-Нови Сад 1988, 111-118.

\section{Cüppers 1974}

Cüppers H., Getreideproduktion und Getreidehandel im Trierer Land zur Römerzeit, Kurtrierisches Jahrbuch 14, Trier 1974, 238-241.

\section{Körber-Gröhne 1987}

Körber-Gröhne M., Nutzpflanzen in Deutschland (Kulturgeschichte und Biologie), Stuttgart 1987.

\section{Kreuz 1995a}

Kreuz A., Landwirtschaft und ihre ökologischen Grundlagen in den Jahrhunderten um Christi Geburt: zum Stand der naturwissenschaftlichen Untersuchungen in Hessen, Berichte der Kommission für Archäologische Landforschung in Hessen 3, 1994/1995, Bonn 1995, 59-91.

\section{Kreuz 1995b}

Kreuz A., Funktionale und konzeptionelle archäobotanische Daten aus römerzeitlichen Brandbestattungen, Berichte der Kommission für Archäologische Landesforschung in Hessen 3, 1994/95, Bonn 1995, 93-97.

\section{Rösch 1992}

Rösch M., Human impact as registered in the pollen record: some results from the western Lake Constance region, Southern Germany, Vegetation History and Archaeobotany 1, Heft 2, 1992, 101-109.

\section{Struck 1993}

Struck M., Busta in Britannien und ihre Verbindungen zum Kontonent (Allgemeine Überlegungen zur Herleitung der Bestattungssitte), Römerzeitliche Gräber als Quelle zu Religion, Bevölkerungsstruktur und Sozialgeschichte, Mainz 1993, 81-94. 